\title{
Mobile Application Development for Spectral Signature of Weed Species in Rice Farming
}

\author{
Nor Athirah Roslin ${ }^{1}$, Nik Norasma Che'Ya ${ }^{1 *}$, Nursyazyla Sulaiman', \\ Lutfi Amir Nor Alahyadi ${ }^{1}$ and Mohd Razi Ismail ${ }^{2}$ \\ ${ }^{1}$ Department of Agriculture Technology, Faculty of Agriculture, Universiti Putra Malaysia, 43400 UPM, \\ Serdang, Selangor, Malaysia \\ ${ }^{2}$ Institute of Tropical Agriculture and Food Security, Universiti Putra Malaysia, 43400 UPM, Serdang, \\ Selangor, Malaysia
}

\begin{abstract}
Weed infestation happens when there is intense competition between rice and weeds for light, nutrients and water. These conditions need to be monitored and controlled to lower the growth of weeds as they affected crops production. The characteristics of weeds and rice are challenging to differentiate macroscopically. However, information can be acquired using a spectral signature graph. Hence, this study emphasises using the spectral signature of weed species and rice in a rice field. The study aims to generate a spectral signature graph of weeds in rice fields and develop a mobile application for the spectral signature of weeds. Six weeds were identified in Ladang Merdeka using Fieldspec HandHeld 2 Spectroradiometer. All the spectral signatures were stored in a spectral database using Apps Master Builder, viewed using smartphones. The results from the spectral signature graph show that the jungle rice (Echinochloa spp.) has the highest near-infrared (NIR) reflectance. In contrast, the saromacca grass (Ischaemum rugosum) shows the lowest NIR reflectance. Then, the first derivative (FD) analysis was run to visualise the separation of each species, and the $710 \mathrm{~nm}$ to $750 \mathrm{~nm}$ region shows the highest separation. It shows that the weed species can be identified using spectral signature by FD analysis with accurate separation.

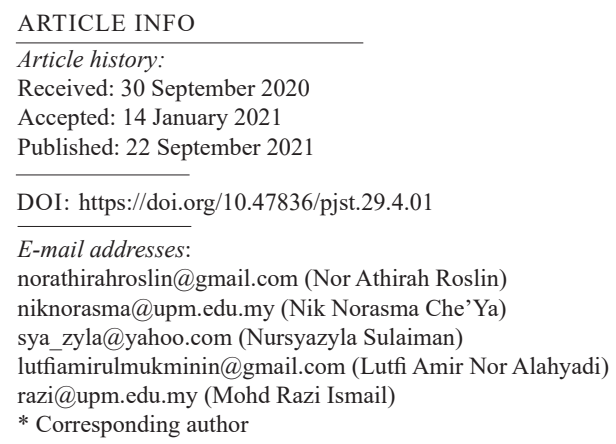

The mobile application was developed to provide information about the weeds and control methods to the users. Users can access information regarding weeds and take action based on the recommendations of the mobile application.

Keywords: Mobile application, rice farming, spectral signature, weed species
\end{abstract}




\section{INTRODUCTION}

Rice is considered a security commodity. The national policy is to maintain a prudent level of self-sufficiency, 65\% at minimum (Vaghefi et al., 2016). One-fifth of the world population or more than a billion households in Asia, Africa, and America rely on the rice systems as their primary source of employment and livelihoods. Apart from this, statistics have proven that the rice industry in Malaysia had created a stable income for the country. However, according to the Department of Statistics Malaysia in 2018, there is a decrease in the rice production in 2017 from 2,739 tonnes to 2,539 tonnes after one year. Many factors caused the decrease of production in paddy, such as climate change (Alam et al., 2012), the changes of planting method from transplanting to direct-seeding (Dilipkumar et al., 2018), field management (Yuhao et al., 2020), and weed infestation such as weedy rice (Man \& Zain, 1998). The yield reduction is high if there is a high weed infestation in the rice field (Jabran et al., 2018). Furthermore, Sudianto et al. (2016) stated that similar to Southeast Asian countries, Malaysia faced problems with the infestation of weedy rice because the establishment methods changed from transplanting of seedlings to direct seedling. Ishak et al. (2013) stated that agricultural activities do not meet the optimal production of crops due to pest and weed issues, weather changes, extreme solar radiation, and exploration.

Weed is an infamous pest that affects yield production all around the world. Around $10 \%$ to $35 \%$ yield losses have been recorded in Malaysia (Karim et al., 2004). Infestations of weedy rice could cut harvests by $80 \%$ if not tested. It will be a crucial constraint to the United States and other world regions relying on rice production (Vigueira et al., 2019). The matter is severe as weed causes problems if farmers are not proactive in its management or control method. The wide adoption of the direct-seeding system has led to a substantially increased infestation and spread of millennial weeds in Malaysia, especially the establishment of weedy rice in the 1980s and after that (Ruzmi et al., 2017). During direct seeding, the threat of weed infestation is a cause of concern and is unavoidable (Matloob et al., 2015).

Precision agriculture is known as site-specific farming that has potential methods to manage crop fields (Tang et al., 2016). It is a combination of several technologies such as global positioning system (GPS), remote sensing (RS) technology, geographic information system (GIS), and physical sensors that collect data of growth traits and yield of fields and carries out various kinds of management (Lin et al., 2019). For example, Roslan et al. (2013) used microwave and machine vision application as the rapid detection method in determining the surface of Dioscorea hispida rhizome alkaloid content. They found that the method can be used to visualise the colours on the D.hispida rhizome peel. This technique is beneficial to many parties and solves ineffective traditional agricultural practices while increasing yield productivity. Productivity increase is essential with the rising human population. The demand for rice increases along with global rice farming and goods (Tang et al., 2016). 


\section{Weed Control Management in Rice Field}

Weed control management is crucial to prevent yield losses. It cuts the cost of production while maintaining the quality of grain. Weed control management helps to reduce weed infestation and prevents the growth of weed seed banks in soil (Labrada, 2003). Poor weed management control affects crops negatively, causing competition between the crops and weeds for sunlight, nutrients, and water. In addition, it increases the cost of production for hired labour and input cost to control the weeds. Furthermore, it causes low yield due to the losses and lowers grain quality which lowers the price. Therefore, weed control should be implemented before planting the seed as early as possible to avoid weed infestation. During the land preparation stage, weed control should be applied to reduce weed infestation in the field. Weed control shall continue until planting the seed in the fields because weed growth is crucial until the paddy matures.

\section{Weed Detection using Remote Sensing and Mobile Applications in Agriculture}

Differences between weeds and crops are hard to detect because they have similar shapes and colour. Each weed species can be identified based on distinct spectral signatures. Remote sensing technology was used for weed detection using spectral reflectance and crop spectral reflectance (Bajwa et al., 2015). The colour infrared photography method provides a better weed screening between the crops (Medlin et al., 2000). Razali et al. (2009) opined that objects could be characterised using colour as a fundamental physical property. It is used to identify the maturity phase and harvesting process for products in agriculture. The light intensity could change the red-green-blue composition of agricultural products due to the variation of daylight. The colour and texture of a high-resolution red-green-blue image and reflectance of a low-resolution multispectral image are combined to detect weeds in rice fields. This combination will produce a fused red-green-blue and multispectral image combination with better weed discrimination features (Barrero \& Perdomo, 2018). The reflective indices of the near-infrared spectrum are visible in the form of colour variability compared to the red-green-blue spectrum (Price, 1994). In addition, weed detections can be made through hyperspectral imaging (HSI), which captures data in hundreds of narrow bands, and has shown promising results when performing per-pixel classification (Wendel \& Underwood, 2016). Each weed species has a unique spectral signature and reflectance (Figure 1). In addition, the leaf pigments, cell structure, and water content are different for each weed species. Based on these differences, weed species can be detected (Abdulridha et al., 2016). Unfortunately, most farmers cannot identify rice diseases, pests, and weeds in the fields because they have limited access to the latest data and information to control pests, especially weeds (Adesina et al., 1994). 


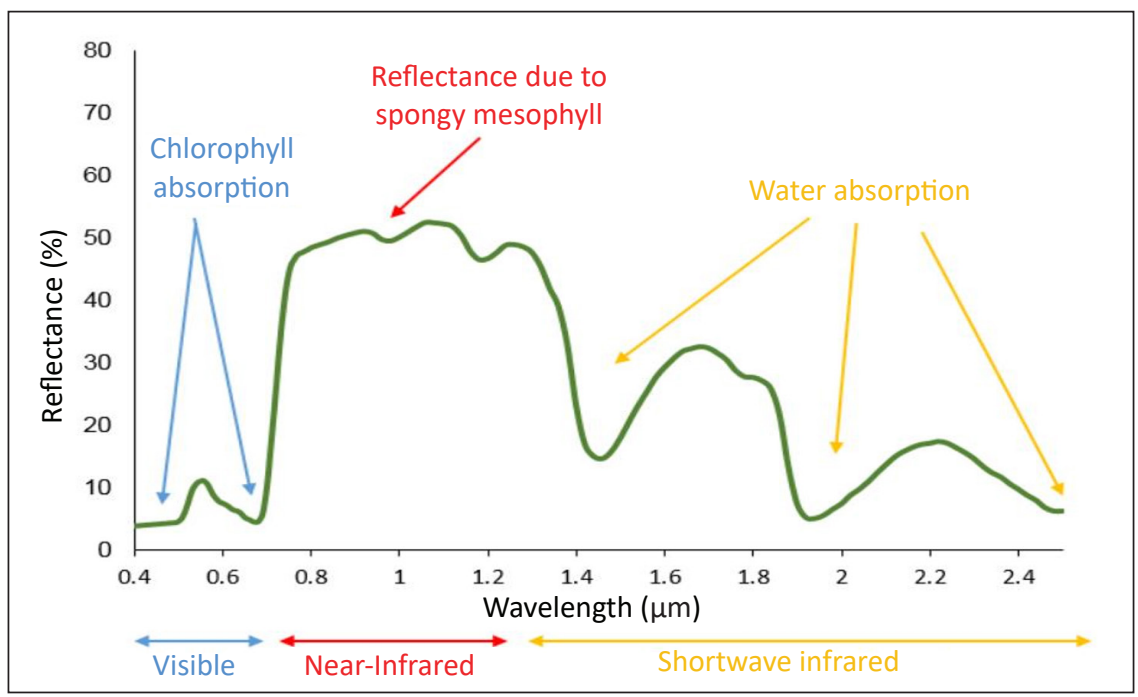

Figure 1. Vegetation spectral reflectance curve (Jensen, 2015)

\section{The Development of Mobile Applications for Utilisation in the Rice Field}

For the future of agriculture, the development of mobile applications is a significant initiative to create more advanced agriculture practices. The rapid growth of beneficial mobile applications and the advancement of mobile phones or smartphones, make these devices essential for farmers nowadays (Pongnumkul et al., 2015). Furthermore, most mobile applications are small in size. Therefore, they would not burden their smartphones and serve them with many features such as managing their data, machinery, orders, maps and navigation, and calendar (Desrial \& Indriawardhana, 2019). Via an application that can detect a plant with a disease where it performs a survey and observation that minimises harm to the plants with a quick outcome. The result from the survey and observation can be a reference for the management of other crops in the future (Zhang et al., 2019).

Many rice-producing countries also have developed mobile applications. For example, Malaysia's advanced and available applications in Google Playstore are MARDI MyPerosakPadi, MARDI Padi Aerob, Rice Check Padi, and Agrimaths. These mobile applications can help users or farmers gain knowledge or information in managing paddy and rice from the start (planting) till the end (harvesting) (Rosle et al., 2019). Usually, in rice production, there is a problem with nutrient deficiency. Therefore, mobile applications can assist farmers to measure the correct levels of nitrogen in paddy plants (Dela Cruz, 2019). Other than that, high accuracy of grain counting can be done, providing quick results (Liu et al., 2017).

Weed infestation in crops is a serious matter to the farmers. It can cause many problems related to the plant from the start of planting up to the yield phase. Smartphones can increase farmers' income opportunities and solve vulnerabilities in the rural areas of less-developed 
countries for smallholder farmers (Ramli et al., 2019). Identification of weed in crops is vital because it relates to the farmers' strategy and decision to manage the fields (Henson et al., 2017). Other than that, farmers can identify the weeds they are not familiar with by using a mobile application (Rahman et al., 2015). Table 1 shows the mobile apps for weed management in crop fields. WeedID and Padi2U provide information regarding weeds and how to control them. At the same time Adebayo et al. (2018) show the recommended weed management at different rice growth stages. Rahman et al. (2015) and Haug et al. (2014) used images to identify the weeds and recommend how to treat the weeds. All these applications are helpful but lack the spectral information of weed species. According to $\mathrm{Su}$ (2020), the spectral signature can be used to identify the weed species in high accuracy compared to image identification.

Spectral signature for plants is essential because it shows the unique value and the characteristics of the plant's species. The same goes for the weeds, as the spectral signature can be visualised using the spectral signature graph. Each spectral signature of weeds species has a different graph curve based on the specific characteristics. Therefore, a spectral library can be used to compare the reflectance of weeds and plants in a field and estimate the infestation percentage in the field (Yang \& Kong, 2017). Furthermore, the spectral signature library can be used to discriminate and identify the plant location. Thus, the mapping of plant varieties can be done (Rao, 2008). The spectral signature graph is stored in the spectral signature library in a digital database to protect from loss and for easy access by researchers worldwide (Rossel et al., 2016). Digital database such as United States Geological Survey (USGS) Spectral Library Version 7 contains reflectance spectra including samples of minerals, rocks, soils, physically constructed, and mathematically

Table 1

Mobile application for weed management

\begin{tabular}{ll}
\hline Mobile application & Description \\
\hline $\begin{array}{l}\text { WeedID } \\
\text { (Henson et al., 2017) }\end{array}$ & $\begin{array}{l}\text { To identify weed using weed images, common name, scientific name, } \\
\text { family name, weed characteristic, habitat, and method to control. } \\
\text { Padi2U } \\
\text { (Athirah et al., 2020) } \\
\text { common name, family name, description, weed habitat, and suggested } \\
\text { method to control. }\end{array}$ \\
$\begin{array}{l}\text { RiceAdvice-Weed Manager } \\
\text { (Adebayo et al., 2018) }\end{array}$ & $\begin{array}{l}\text { Provide recommended weed management at different rice growth } \\
\text { stages. Weed information in the mobile application is based on farmers' } \\
\text { knowledge. However, expert advice is provided for the best method to } \\
\text { control the weed. }\end{array}$ \\
$\begin{array}{l}\text { A mobile application using image } \\
\text { analysis }\end{array}$ & $\begin{array}{l}\text { Images captured and uploaded into the system, which identifies the } \\
\text { image using a hierarchical system. The first level consists of non- } \\
\text { experts and, the second level is from the experts. }\end{array}$ \\
$\begin{array}{l}\text { Crop and weed identification } \\
\text { using plant classification }\end{array}$ & $\begin{array}{l}\text { From the image captured by the user, the system will identify the weed } \\
\text { and come out with the recommended method to control the weed. }\end{array}$ \\
\hline
\end{tabular}


computed mixtures, plants, vegetation communities, microorganisms, and artificial materials (Kokaly et al., 2017). Most conventional spectral libraries focus on minerals, and urban areas' temperature, where the primary information was soil. Examples of soil and minerals spectral libraries are ASTER Spectral Library, John Hopkin Spectral Library, Jet Propulsion Laboratory Spectral Library, MedSpec, and LILIAN (Adam, 2012). Vegetation spectral library was created in South China to store spectral data, different growth periods of various crops, and providing analysis with control strategy management of crops to the users (Chen et al., 2005).

Two spectral libraries of a selected tropical rainforest were designed and developed to store the data of vegetation spectra such as leaf condition, vigorous, and other physiological and biological parameters (Lau \& Hashim, 2007). Other than that, the rubber trees disease spectral library was developed to identify the spread of disease in a large area (Jusoff et al., 2010). All spectral libraries were developed on particular observation and mostly are inaccessible to public users. However, the spectral library for weed species in rice farming is an excellent start to store all spectral signatures for current use and the future. Hence, we developed a mobile application for weed management to replace the prior paper-based system and provide a spectral signature database of weed species accessible via mobile application.

\section{MATERIALS AND METHODS}

The study area is located at Ladang Merdeka, Kampung Lundang Paku, Ketereh, Kelantan with coordinate $5^{\circ} 59^{\prime} 3.0804^{\prime \prime} \mathrm{N}, 102^{\circ} 12^{\prime} 24.0012^{\prime \prime} \mathrm{E}$ and the total area of the field are $70,692.59 \mathrm{~m}^{2}$ (Figure 2). The area is a well-organised plot, and the variety of the paddy

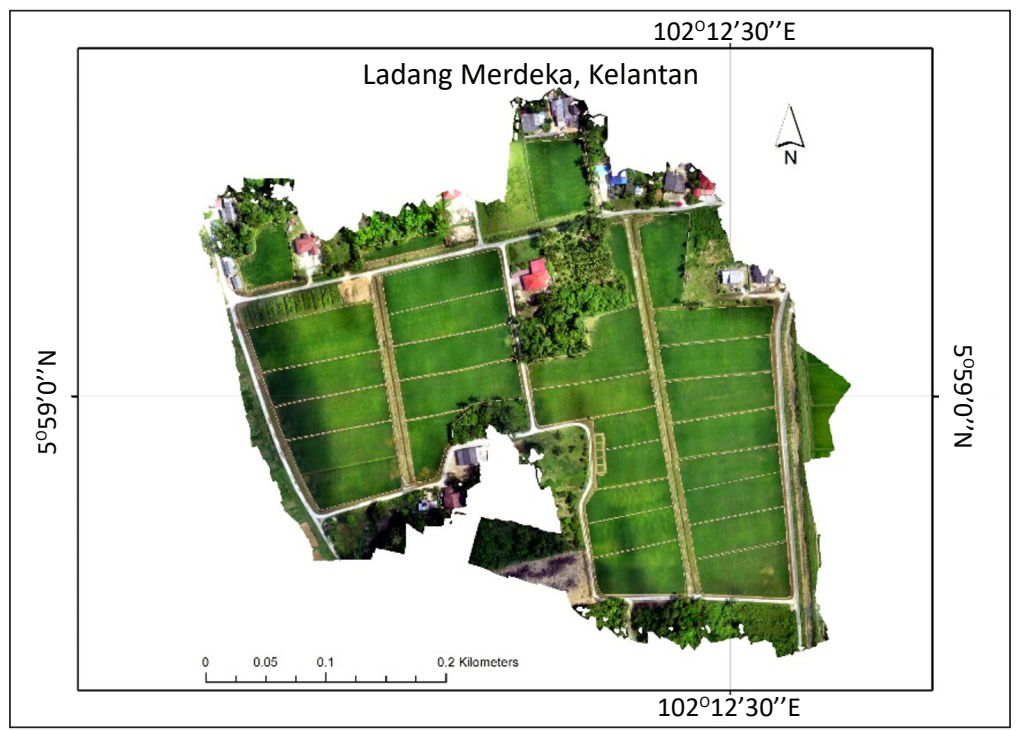

Figure 2. Experimental plot in Ladang Merdeka 
seed is PadiU Putra. This paddy seed is a new variety, resistant to leaf blight disease, as discovered by UPM researchers.

\section{Data Collection}

Hyperspectral reflectance data were collected using a ASD FieldSpec ${ }^{\circledR}$ HandHeld 2 spectroradiometer (Malvern Panalytival, Cambridge, United Kingdom). The benefits of using FieldSpec ${ }^{\circledR}$ HandHeld 2 spectroradiometer is that it is cost-effective, user-friendly, versatile, and durable (ASDi, 2014). In addition, it has a highly sensitive detector array with a low stray light grating, a built-in shutter, DriftLock dark current compensation, and second-order filtering that produces a high signal-to-noise spectrum in under one second (ASDi, 2014) (Table 2).

Spectral signatures of weed were collected in 2018 at 9:00 am under the clear sky field conditions. The weed species collected were saromacca grass (Ischaemum rugosum), lesser fimbristylis (Fimbristylis miliacea), red sparangletop (Leptochloa chinensis), weedy rice (Oryza sativa L.), jungle rice (Echinochloa spp.), and flower of jungle rice (Echinochloa spp.) (Table 3). The calibration process was done using the white panel provided by the Analytical Spectral Device Corporation (ASD), Inc., Boulder, CO, USA. The white panel diffuses the reflection by nearly $100 \%$ of the incident light throughout the spectral range. In other words, the reflectance value of the white reference panel is nearly one at every wavelength (ASDi, 2014). Each weed was collected for ten samples at random between $5 \mathrm{~cm}$ distance of the optical sensor and the sample. This technique is used to avoid error and noise for data recording (Norasma, 2016).

Table 2

FieldSpec ${ }^{\circledR}$ HandHeld 2 Spectroradiometer properties (ASDi, 2014)

\begin{tabular}{ll}
\hline Specification & \multicolumn{1}{c}{ Information } \\
\hline Design & $\begin{array}{l}\text { An ergonomic dual position } \\
\text { "D" handle }\end{array}$ \\
Weight & $1.17 \mathrm{~kg}$ including batteries \\
Wavelength Range & $325 \mathrm{~nm}-1075 \mathrm{~nm}$ \\
Accuracy & $\pm 1 \mathrm{~nm}$ \\
Optional GPS & Yes \\
\hline
\end{tabular}

Table 3

Weed species collected using a spectroradiometer (Analytical Spectral Device Corporation (ASD), Inc., Boulder, CO, USA)

\begin{tabular}{lc}
\hline Weed species & Abbreviation \\
\hline Saromacca grass (Ischaemum rugosum) & IR \\
Lesser fimbristylis (Fimbristylis miliacea) & FM \\
Red sparangletop (Leptochloa chinensis) & LC \\
Weedy rice (Oryza sativa L.) & OSL. \\
Jungle rice (Echinochloa spp.) & E \\
Flower of jungle rice (Echinochloa spp.) & FE \\
\hline
\end{tabular}




\section{Data Analysis}

All the raw data were transferred to a computer using a USB cable. First, the data was saved in a Microsoft Excel spreadsheet. Then, the data were binned into $10 \mathrm{~nm}$ spectral band each compared to $1 \mathrm{~nm}$ originally (Figure 3). Next, the spectral signature was visualised in the spectral reflectance graph for each species using Microsoft Excel. Then, the first derivative was run and visualised using Microsoft Excel as the steps below:

(a) Spectral Reflectance Visualisation

The spectral reflectance for all species was visualised graphically using Microsoft Excel step 3 (Figure 3).

(b) First Derivative Analysis

The first derivatives were calculated using Equation 1 in MS Excel and displayed in step 4 (Figure 3).

$$
F D=\frac{R}{R}=\frac{R y_{2}-R y_{1}}{\lambda x_{2}-\lambda x_{1}}
$$

Where:

$\mathrm{FD}=$ First Derivative

$\mathrm{Ry}_{1}, \mathrm{Ry}_{2}=$ Reflectance of the first and second reflectance pairs $\mathrm{n} 1$ and $\mathrm{n} 2$

$\lambda \mathrm{x}_{1}, \lambda \mathrm{x}_{2}=$ Wavelength of first and second reflectance pairs $\mathrm{n} 1$ and $\mathrm{n} 2 \mathrm{n}=$ Position of reflectance.

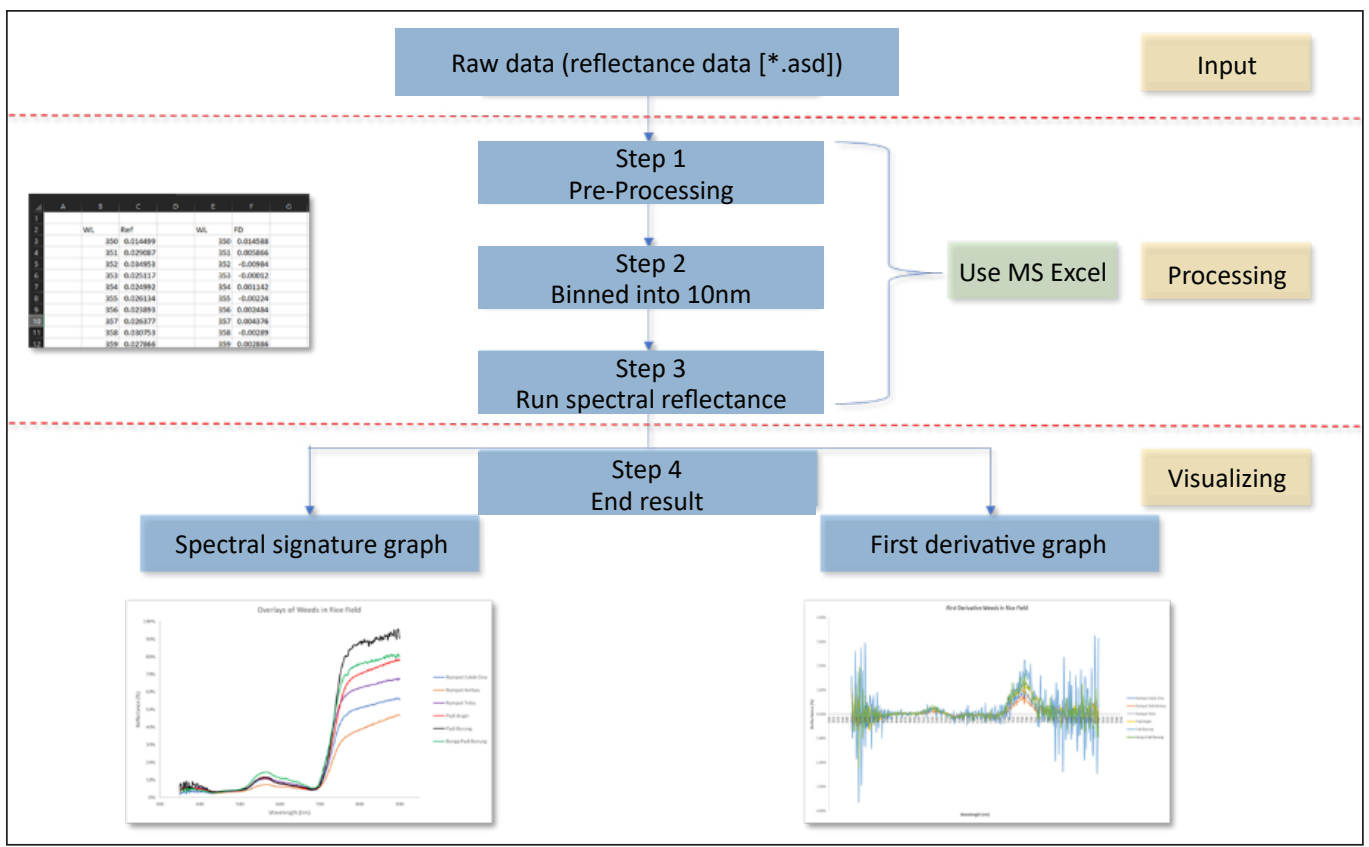

Figure 3. Hyperspectral data download and pre-processing (Lutfi, 2020) 


\section{Mobile App Development}

The platform used to build this application is an online website called https:// masterappsbuilder.com. This website is commercial software to develop a mobile application. It is user friendly and easy to use. Figure 4 shows the main menu of the website that contains the list of applications. The statistics data about the number of apps installed on Android and IOS devices is shown on the website. Other than that, it shows the number of visitors to the mobile application. The editor menu is shown after selecting the application on the list. The application menu contains a few functions: design, colours, features, application, and publication (Figure 4). The building application interface is located under the feature function menu. The data were stored in the database that can be displayed on the application through the function features (Figure 4).

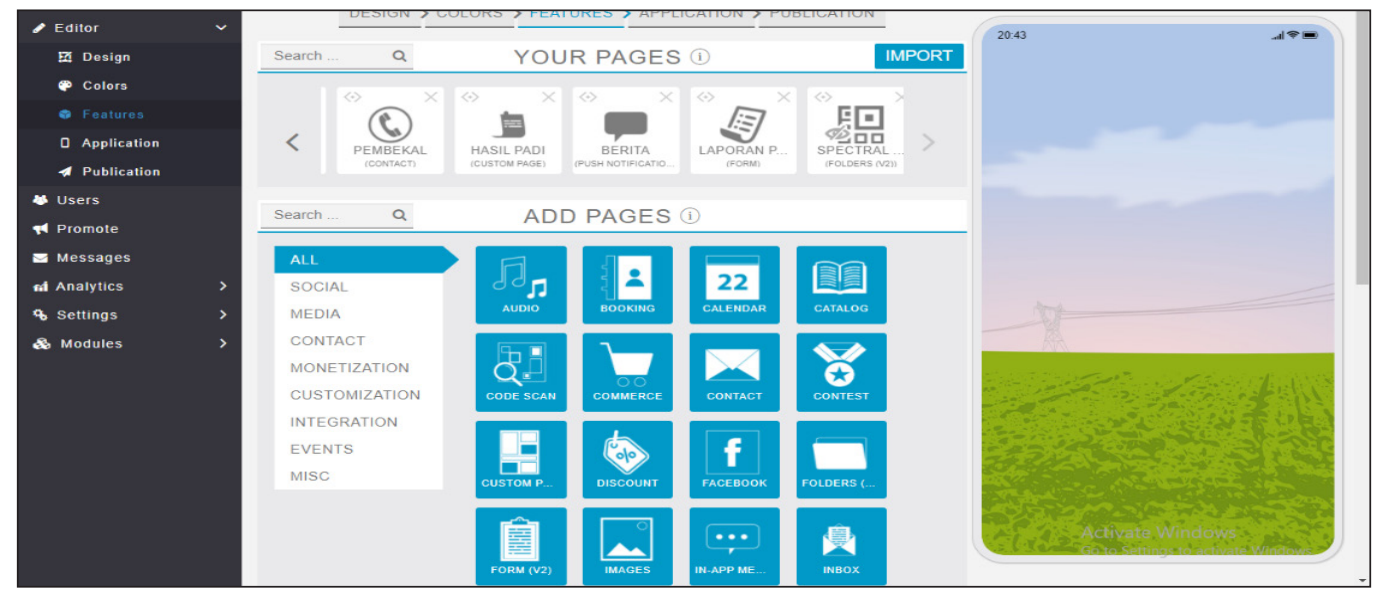

Figure 4. The application Editor feature and Feature menu in MasterAppBuilder

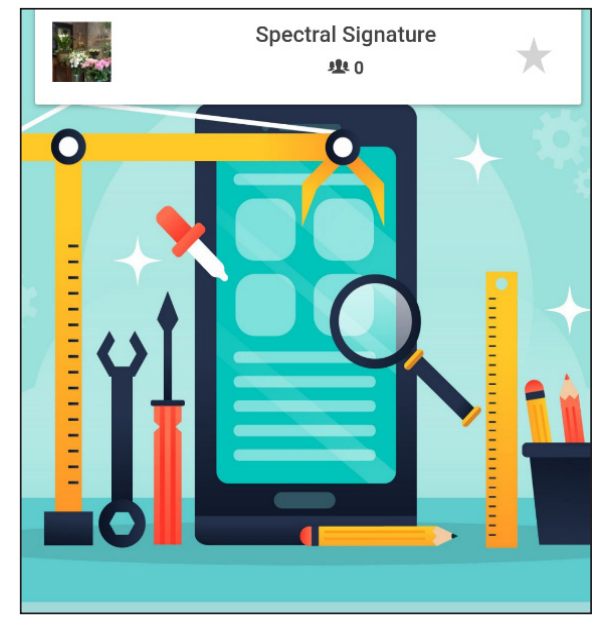

Figure 5. List of applications built-in the MasterAppBuilder website
Application preview is a preview interface for mobile apps using AMB previewer. It shows how the application works on the android or IOS device (Figure 5). On the previewer page, the user only can view the mobile apps without any editing features. This application can be downloaded at Google Playstore or Appstore in IOS.

\section{RESULTS AND DISCUSSION}

\section{Spectral Signature Graph}

The spectral reflectance profile is shown graphically for each type of weed (Figure 6), a low reflectance in the visible region with slight 
peaks in the green region. An increase begins at $690 \mathrm{~nm}$ reaching the static line in the near-infrared region. It is an ordinary green plant spectral reflectance. The percentage difference in reflectance between weeds at one wavelength and weeds at another wavelength is enormous.

Species differences show up at specific wavelengths. For example, in the visible spectrum (450 $\mathrm{nm}$ to $700 \mathrm{~nm}$ ), all weed spectral signatures were very similar, and many overlapped. At the same time, for the infrared region (700 nm to $990 \mathrm{~nm})$, the spectra of different species are separated by their different wavelengths (Figure 6).

Jungle rice (Echinochloa spp.) had the highest NIR reflectance than other weed species (Figure 6). The second highest reflectance was its flower of jungle rice (Echinochloa spp.), followed by weedy rice (Oryza sativa L.). Lesser fimbristylis (Fimbristylis miliacea) had the lowest reflectance, followed by saromacca grass (Ischaemum rugosum). Finally, the red sparangletop (Leptochloa chinensis) had reflectance spectra from the other weeds (Figure 6).

Figures 7 to 12 show the spectral signatures for individual weed species such as saromacca grass (Ischaemum rugosum), lesser fimbristylis (Fimbristylis miliacea), red sparangletop (Leptochloa chinensis), weedy rice (Oryza sativa L.), jungle rice (Echinochloa spp.) and Jungle rice flowers (Echinochloa spp.) respectively.

Figure 13 shows the first derivative graph for each weed species. It clearly shows the $710 \mathrm{~nm}$ to $750 \mathrm{~nm}$ regions of the weed species separately. It can be an indicator to identify the weed species in this region. This region is known as the Near InfraRed region where it is related to the photosynthesis process. Since each weed is different, the significant bands for each weed can be seen in this region $(710 \mathrm{~nm}$ to $750 \mathrm{~nm})$. NIR is related to the biogeochemical and leaf pigments of the weed species (Jensen, 2015). Thus, this region is essential as an indicator to differentiate the weed species by using spectral signature.

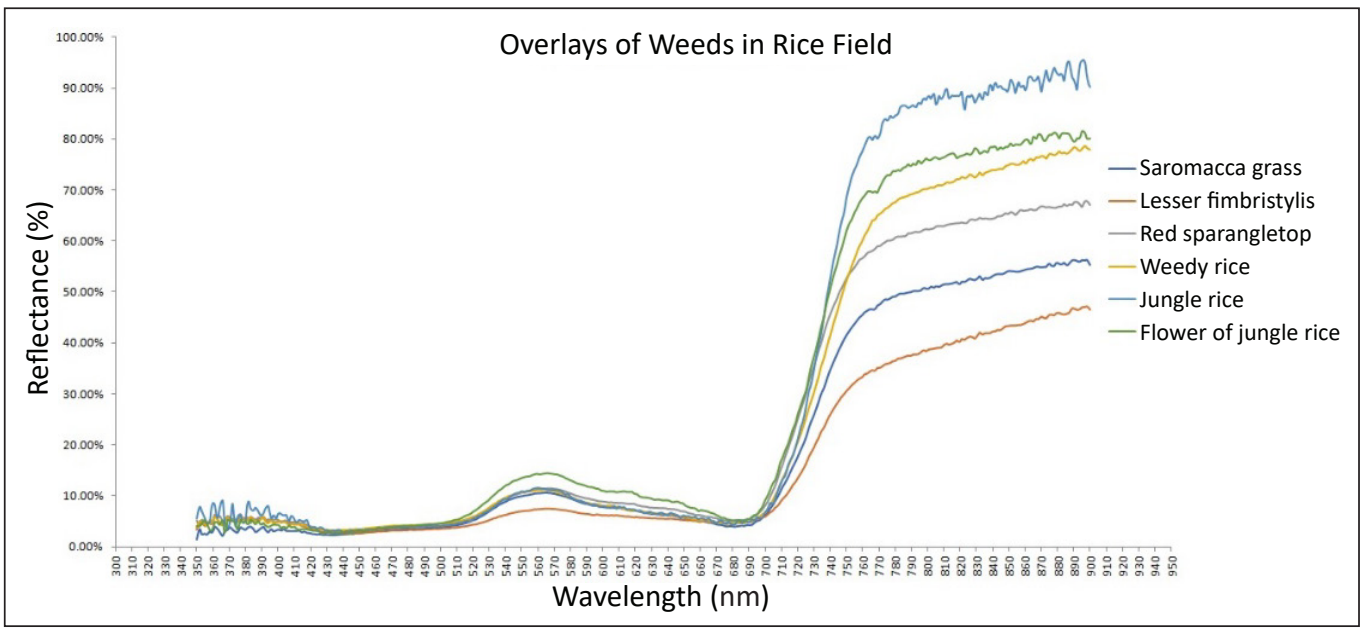

Figure 6. Overlays of spectral reflectance graph of weeds 


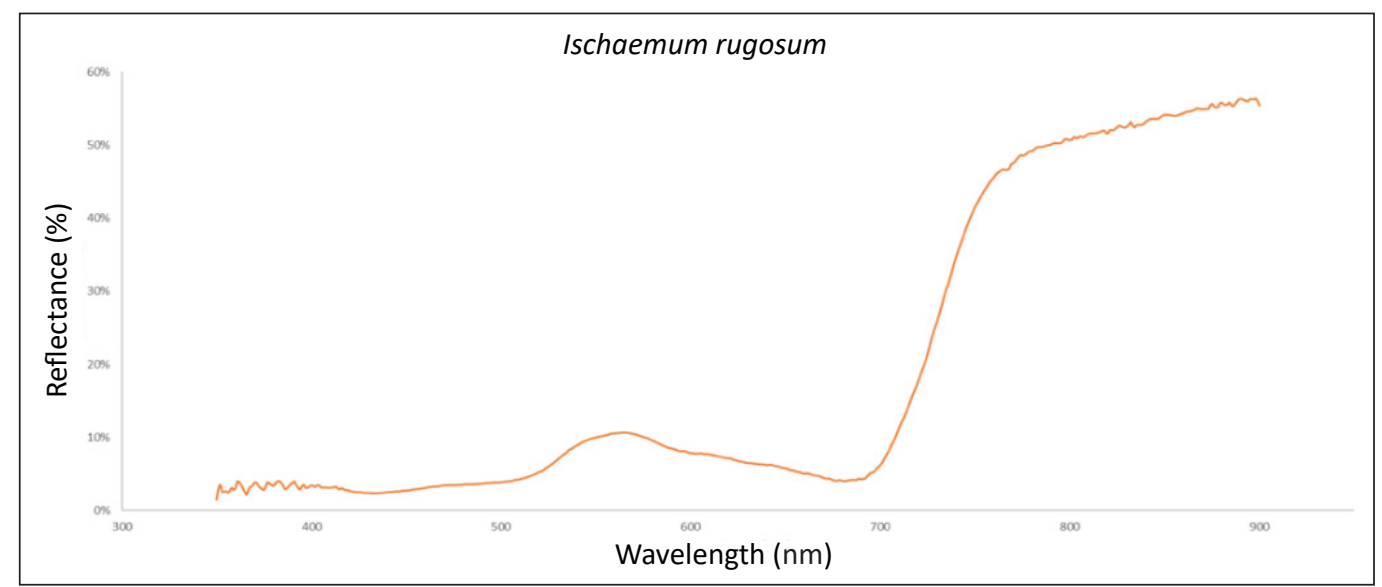

Figure 7. Spectral reflectance graph of Saromacca grass (Ischaemum rugosum) (Norasma et al., 2020)

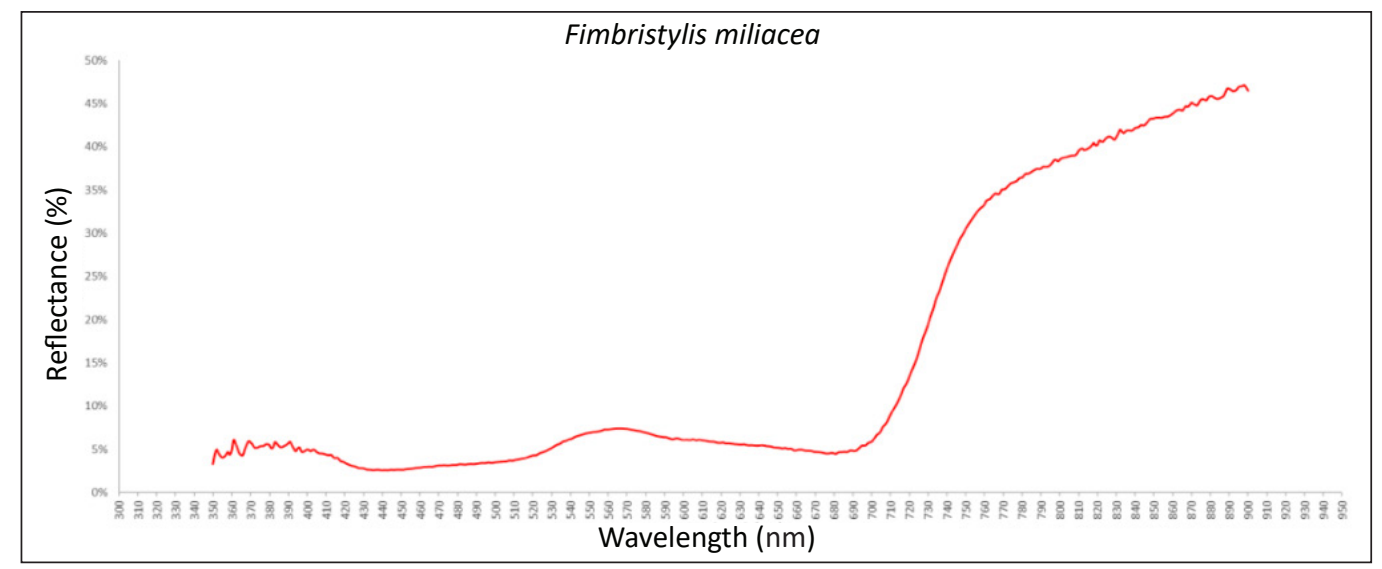

Figure 8. Spectral reflectance graph of Lesser fimbristylis (Fimbristylis miliacea) (Norasma et al., 2020)

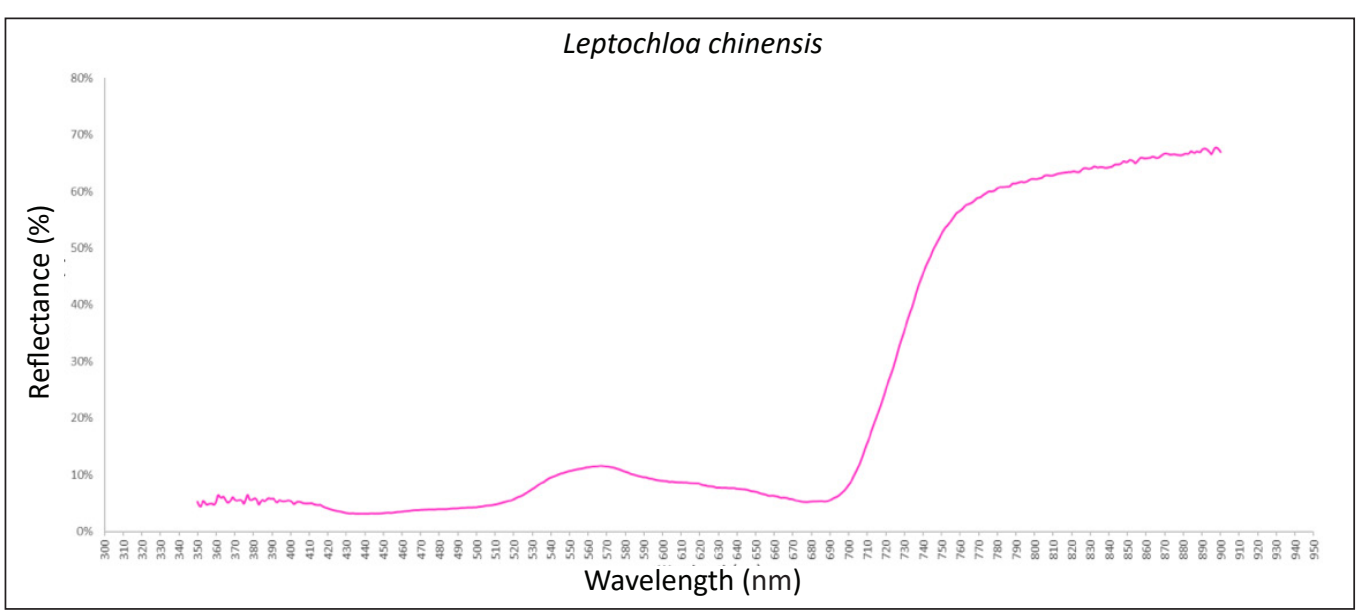

Figure 9. Spectral reflectance graph of Red sparangletop (Leptochloa chinensis) (Norasma et al., 2020) 


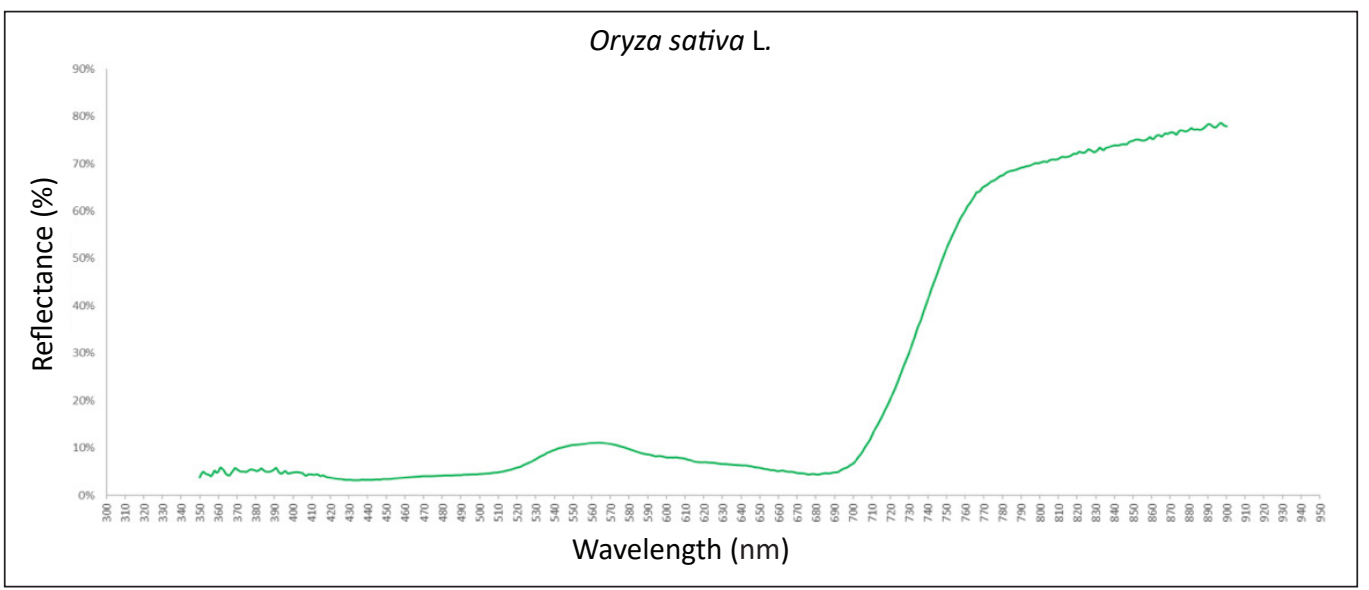

Figure 10. Spectral reflectance graph of Weedy rice (Oryza sativa L.)

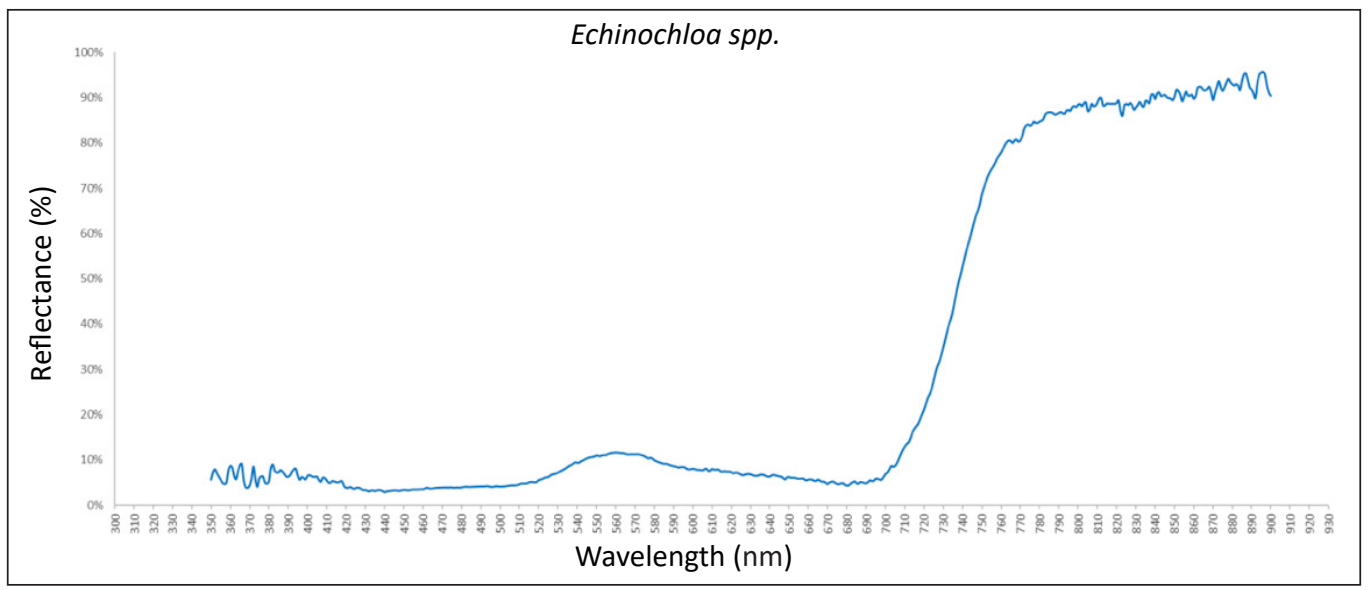

Figure 11. Spectral reflectance graph of Jungle rice (Echinochloa spp.)

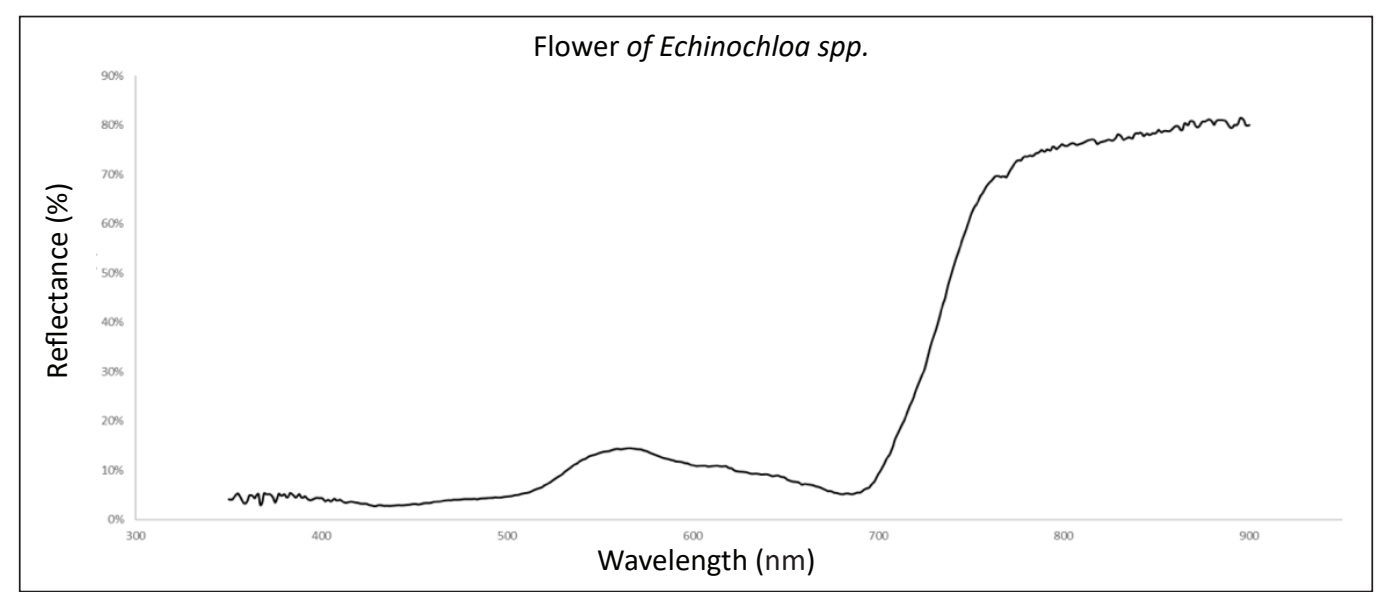

Figure 12. Spectral reflectance graph of Jungle rice's flowers (Echinochloa spp.) 


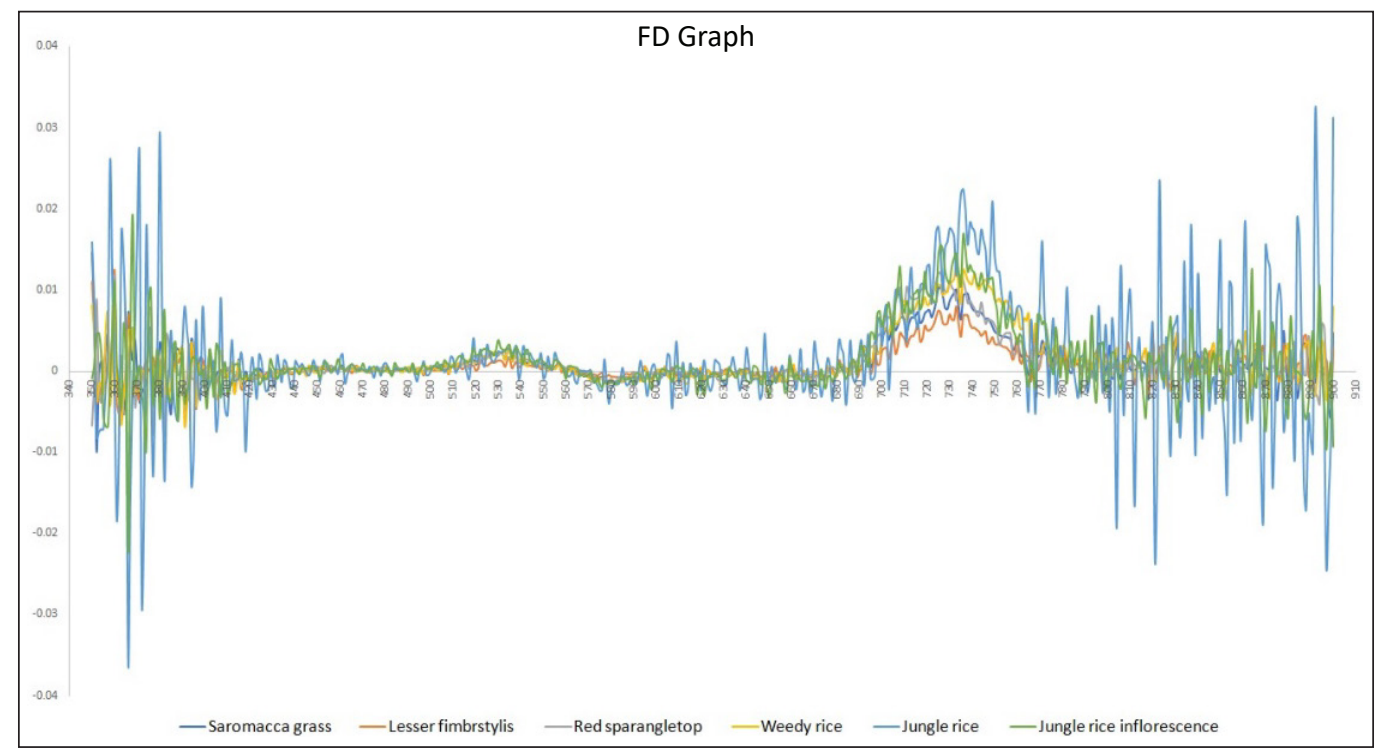

Figure 13. First derivative graph of weeds in KADA rice field

\section{User Interface Mobile Application}

A mobile app was successfully developed using the MasterAppBuilder. Figure 14 shows the main menu for the mobile app. It contains weed information, the spectral signature of weeds, and guidelines on how to control the weeds. The spectral library menu contains information about the six weeds that had been studied in the project. User can download the mobile application into their smartphones. The mobile application works by providing the image of the weed species, general name, scientific name, description, a method to control using a chemical application, and spectral signature graph of the weed species (Figure 14). Users can peruse the information provided in the mobile application to identify the weeds in their field based on the image and its description. A database of weed information, including spectral signatures is stored in this mobile application. Users can easily access it from their mobile devices. This mobile application offers a spectral signature graph that makes a difference compared with previous mobile apps available (Table 1). The WeedID developed by Henson et al. (2017) only provides the image of the weeds, its detailed description, and method to control. The same method was used to develop Padi2U mobile application, which offers the weed images, descriptions, and recommended methods to control (Athirah et al., 2020). The other mobile application developed was based on the image captured by the user. The system will identify the weed images and provide the method to control the weeds (Haug et al., 2014; Rahman et al., 2015). Thus, in this study, we introduce the spectral signature of six species of weeds that are commonly found in the study area. It can be a reference for the user to see the spectral signature of each weed. 


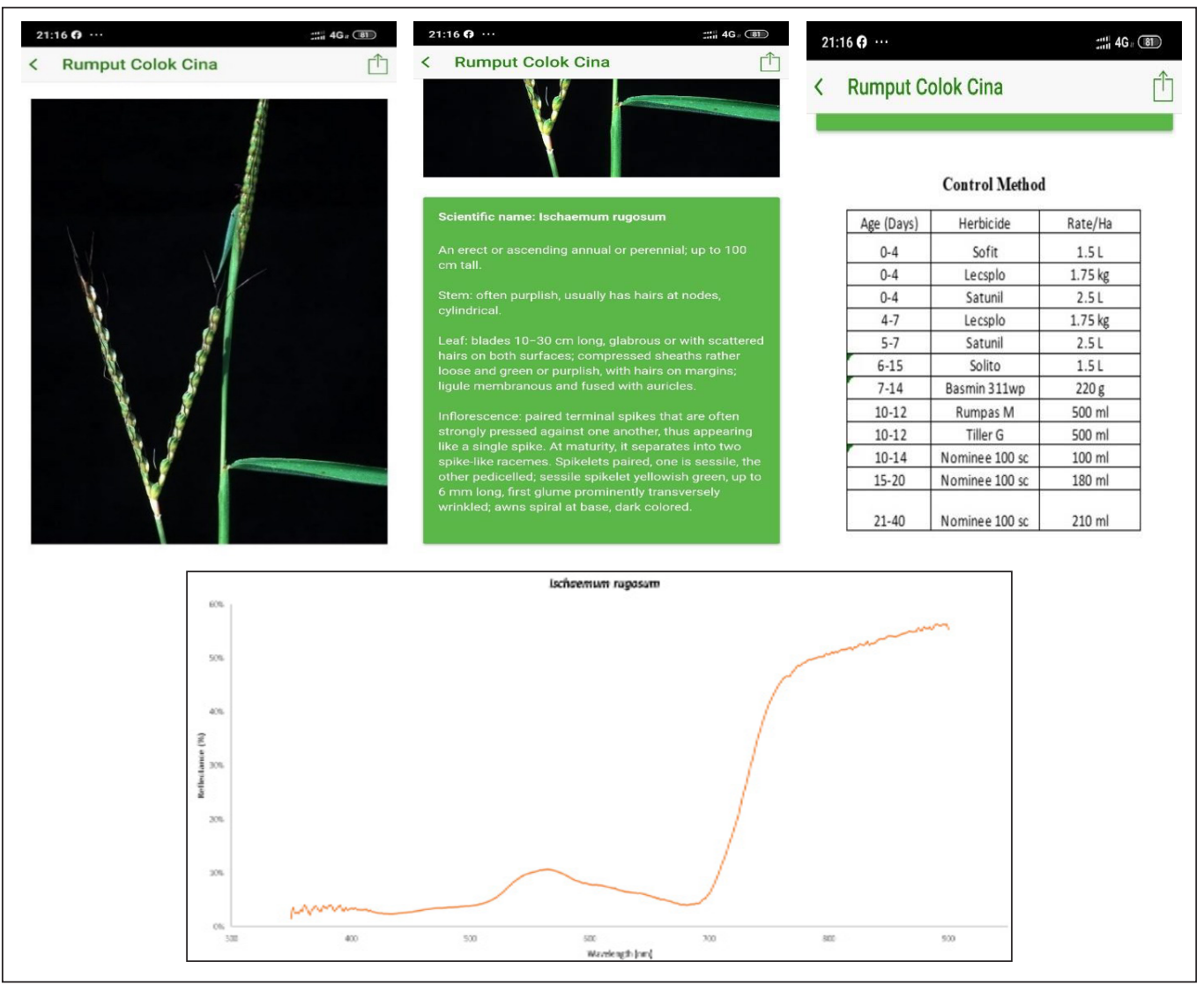

Figure 14. The content of menus, pictures, description, control method, and spectral signature graph (AMB Previewer)

\section{CONCLUSION AND FUTURE DIRECTION}

Detecting weeds visually in a large rice field area is challenging and time-consuming for farmers. In such a way, the use of mobile applications assists the user to manage weed effectively. This research project connects the spectral signature library and mobile applications that could be a potential use in modern technology to manage weeds in the field. The mobile application can display the spectral signature of the weed and suggest methods to control the weed using chemical control. Other than that, various methods of control can also be given through the mobile application to assist the farmers in overcoming the growth of weeds. Furthermore, the spectral signature can serve as a reference to detect weeds with a hyperspectral sensor in a shorter time instead of using the conventional method, which requires more time to detect the entire rice field thoroughly.

The mobile application can display the spectral signature of weeds, and such information is accessible to farmers via smartphones. Moreover, using a mobile phone or smartphone, users can easily compare the weed that had infested their field with the weed 
information provided in the mobile application. In conclusion, the mobile application integrating spectral signature library can be a modus to display information about weed in the rice field.

Many challenges need to be overcome, such as the limitations in gaining raw data of the spectral signature of the weed in the rice field, the presence of various weeds in the field, the difference of control methods on each type of weed, and the conventional methods that the farmers are still using to detect weed. However, statistical analysis and vegetation index for the spectral reflectance analysis such as discriminant analysis, convolutional neural network (CNN), artificial neural network (ANN), and support vector machine (SVM) will increase the classification results.

\section{ACKNOWLEDGEMENT}

The authors wish to acknowledge Mr Mohd Zalyny Shah Noh and the financial support from the Ministry of Higher Education under Translational PADIU PUTRA Research Grant (Vote No: 5526500), Universiti Putra Malaysia GP-IPM (Vote No: 9611400) and Pest and Disease Monitoring Using Artificial Intelligent for Risk Management of Rice Under Climate Change" under the Long-Term Research Grant Scheme (LRGS), Ministry of Higher Education, Malaysia (LRGS/1/2019/UPM//2; vote number: 5545002). The authors also sincerely acknowledge the University Putra Malaysia for providing facilities.

\section{REFERENCES}

Abdulridha, J., Ehsani, R., \& De Castro, A. (2016). Detection and differentiation between laurel wilt disease, phytophthora disease, and salinity damage using a hyperspectral sensing technique. Agriculture, 6(4), Article 56. https://doi.org/10.3390/agriculture6040056

Adam, S. N. B. (2012). Design and development of an interactive digital spectral library [Unpublished MSc dissertation]. Universiti Putra Malaysia, Malaysia.

Adebayo, S., Ogunti, E. O., Akingbade, F. K., \& Oladimeji, O. (2018). A review of decision support system using mobile applications in the provision of day to day information about farm status for improved crop yield. Periodicals of Engineering and Natural Sciences, 6(2), 89-99. http://dx.doi.org/10.21533/ pen.v6i2.183

Adesina, A. A., Johnson, D. E., \& Heinrichs, E. A. (1994). Rice pests in the Ivory Coast, West Africa: Farmers' perceptions and management strategies. International Journal of Pest Management, 40(4), 293-299. https://doi.org/10.1080/09670879409371902

Alam, M. M., Siwar, C., Toriman, M. E., Molla, R. I., \& Talib, B. (2012). Climate change induced adaptation by paddy farmers in Malaysia. Mitigation and Adaptation Strategies for Global Change, 17(2), 173-186. https://doi.org/10.1007/s11027-011-9319-5

ASDi. (2014). Handheld 2: Hand-held VNIR spectroradiometer. FieldSpec. Retrieved September 26, 2015, from http://www.asdi.com/products/fieldspec-spectroradiometres/handheld-2- portable-spectroradiometer 
Athirah, R. N., Norasma, C. Y. N., \& Ismail, M. R. (2020). Development of an android application for smart farming in crop management. In IOP Conference Series: Earth and Environmental Science (Vol. 540, No. 1, p. 012074). IOP Publishing. https://doi.org/10.1088/1755-1315/540/1/012074

Bajwa, A. A., Mahajan, G., \& Chauhan, B. S. (2015). Nonconventional weed management strategies for modern agriculture. Weed Science, 63(4), 723-747. https://doi.org/10.1614/WS-D-15-00064.1

Barrero, O., \& Perdomo, S. A. (2018). RGB and multispectral UAV image fusion for Gramineae weed detection in rice fields. Precision Agriculture, 19(5), 809-822. https://doi.org/10.1007/s11119-017-9558-x

Chen, S. S., Fang, L. G., Liu, Q. H., Chen, L. F., \& Tong, Q. X. (2005). The design and development of spectral library of featured crops of South China. In Proceedings 2005 IEEE International Geoscience and Remote Sensing Symposium, 2005. IGARSS'05. (Vol. 2, pp. 4-pp). IEEE Publishing. https://doi. org/10.1109/IGARSS.2005.1525234

Dela Cruz, G. B. (2019). Nitrogen deficiency mobile application for rice plant through image processing techniques. International Journal of Engineering and Advanced Technology, 8(6), 2950-2955. https:// doi.org/10.35940/ijeat.F8721.088619

Desrial, \& Indriawardhana, P. A. K. (2019). Design of online application for agricultural machinery service based on android operating system. In IOP Conference Series: Materials Science and Engineering (Vol. 557, No. 1, p. 012023). IOP Publishing. https://doi.org/10.1088/1757-899x/557/1/012023

Dilipkumar, M., Burgos, N. R., Chuah, T. S., \& Ismail, S. (2018). Cross-resistance to imazapic and imazapyr in a weedy rice (Oryza sativa) biotype found in Malaysia. Planta Daninha, v36, Article e018182239. https://doi.org/10.1590/S0100-83582018360100058

Haug, S., Michaels, A., Biber, P., \& Ostermann, J. (2014). Plant classification system for crop/weed discrimination without segmentation. In IEEE Winter Conference on Applications of Computer Vision (pp. 1142-1149). IEEE Publishing. https://doi.org/10.1109/WACV.2014.6835733

Henson, Y., Martin, R., Quinnell, R., Van Ogtrop, F., Try, Y., \& Tan, D. (2017, September 24-28). Development of a weed identifier mobile application for Cambodian rice farmers. In Proceedings of the 18th Australian Society of Agronomy Conference (pp. 1-4). Ballarat, Australia.

Ishak, W. W., Hudzari, R. M., \& Tan, M. Y. (2013). Development of an automation and control design system for lowland tropical greenhouses. Pertanika Journal of Science \& Technology, 21(2), 365-374.

Jabran, K., Uludag, A., \& Chauhan, B. S. (2018). Sustainable weed control in rice. In Weed Control (pp. 276287). CRC Press.

Jensen, J. R. (2015). Introductory digital image processing: A remote sensing perspective. Prentice Hall Press.

Jusoff, K., Yusoff, M. M., \& Ali, N. H. M. (2010). Spectral signatures of leaf fall diseases in Hevea brasiliensis using a handheld spectroradiometer. Modern Applied Science, 4(2), 78-84.

Karim, R. S., Man, A. B., \& Sahid, I. B. (2004). Weed problems and their management in rice fields of Malaysia: An overview. Weed Biology and Management, 4(4), 177-186. https://doi.org/10.1111/j.14456664.2004.00136.x

Kokaly, R. F., Clark, R. N., Swayze, G. A., Livo, K. E., Hoefen, T. M., Pearson, N. C., Wise, R. A., Benzel, W. M., Lowers, H. A., Driscoll, R. L., \& Klein, A. J. (2017). USGS spectral library version 7 data: US geological survey data release. United States Geological Survey (USGS). 
Labrada, R. (2003). The need for improved weed management in rice. In Proceedings of the 20th Session of the International Rice Commission (pp. 181-189). FAO Publishing.

Lau, A. M. S., \& Hashim, M. (2007). The design and building of spectral library of tropical rain forest in Malaysia. In The 28th Asian Conference on Remote Sensing 2007 (Vol. 2, pp. 1150-1157). Asian Association on Remote Sensing.

Lin, C. Y., Chang, S. J., Lai, M. H., \& Lu, H. Y. (2019, August 6-8). Overview of precision agriculture with focus on rice farming. In International Workshop on ICTs For Precision Agriculture (pp. 19-26). Selangor, Malaysia.

Liu, T., Chen, W., Wang, Y., Wu, W., Sun, C., Ding, J., \& Guo, W. (2017). Rice and wheat grain counting method and software development based on Android system. Computers and Electronics in Agriculture, 141, 302-309. https://doi.org/10.1016/j.compag.2017.08.011

Lutfi, A. N. A. (2020). Mobile application development for spectral signature of weed species in rice (Degree Thesis). Univerisiti Putra Malaysia, Malaysia.

Man, A., \& Zain, A. M. (1998). Manual for the identification and control of padi angin (weedy rice) in Malaysia. Malaysian Agricultural Research and Development Institute.

Matloob, A., Khaliq, A., \& Chauhan, B. S. (2015). Weeds of direct-seeded rice in Asia: problems and opportunities. Advances in Agronomy, 130, 291-336. https://doi.org/10.1016/bs.agron.2014.10.003

Medlin, C. R., Shaw, D. R., Gerard, P. D., \& LaMastus, F. E. (2000). Using remote sensing to detect weed infestations in Glycine max. Weed Science, 48(3), 393-398. https://doi.org/10.1614/00431745(2000)048[0393:URSTDW]2.0.CO;2

Norasma, C. Y. N. (2016). Site-specific weed management using remote sensing (PhD Thesis). The University of Queensland, Australia.

Norasma, C. Y. N., Alahyadi, L. A. N., Fazilah, F. F. W., Roslan, S. N. A., \& Tarmidi, Z. (2020). Identification spectral signature of weed species in rice using spectroradiometer handheld sensor. In IOP Conference Series: Earth and Environmental Science (Vol. 540, No. 1, p. 012091). IOP Publishing. https://doi. org/10.1088/1755-1315/540/1/012091

Pongnumkul, S., Chaovalit, P., \& Surasvadi, N. (2015). Applications of smartphone-based sensors in agriculture: A systematic review of research. Journal of Sensors, 2015, Article 195308. https://doi. org/10.1155/2015/195308

Price, J. C. (1994). How unique are spectral signatures? Remote Sensing of Environment, 49(3), 181-186. https://doi.org/10.1016/0034-4257(94)90013-2

Rahman, M., Blackwell, B., Banerjee, N., \& Saraswat, D. (2015). Smartphone-based hierarchical crowdsourcing for weed identification. Computers and Electronics in Agriculture, 113, 14-23. https://doi.org/10.1016/j. compag.2014.12.012

Ramli, N. S., Hassan, M. S., Man, N., Samah, B. A., Omar, S. Z., Rahman, N. A. A., Yusuf, S., \& Ibrahim, M. S. (2019). Seeking of agriculture information through mobile phone among paddy farmers in 
Selangor. International Journal of Academic Research in Business and Social Sciences, 9(6), 527-538. http://dx.doi.org/10.6007/IJARBSS/v9-i6/5969

Rao, N. R. (2008). Development of a crop-specific spectral library and discrimination of various agricultural crop varieties using hyperspectral imagery. International Journal of Remote Sensing, 29(1), 131-144. https://doi.org/10.1080/01431160701241779

Razali, M. H., Ismail, W. I. W., Ramli, A. R., Sulaiman, M. N., \& Harun, M. H. (2009). Development of image based modeling for determination of oil content and days estimation for harvesting of fresh fruit bunches. International Journal of Food Engineering, 5(2), Article 12. https://doi.org/10.2202/1556-3758.1633

Roslan, S., Razali, M. H. H., Ismail, W. I. W., Abbas, Z., \& Zainuddin, M. F. (2013). Rapid detection techniques for mechanical properties determination on surface of Dioscorea hispida rhizome. Procedia Engineering, 68, 446-452. https://doi.org/10.1016/j.proeng.2013.12.205

Rosle, R., Norasma, C. Y. N., Roslin, N. A., Halip, R. M., \& Ismail, M. R. (2019). Monitoring early stage of rice crops growth using normalized difference vegetation index generated from UAV. In IOP Conference Series: Earth and Environmental Science (Vol. 355, No. 1, p. 012066). IOP Publishing.

Rossel, R. V., Behrens, T., Ben-Dor, E., Brown, D. J., Demattê, J. A. M., Shepherd, K. D., Shi, Z., Stenberg, B., Stevens, A., Adamchuk, V., Aichi, H., Barthes, B. G., Bartholomeus, H. M., Bayer, A. D., Bernoux, M., Bottcher, K., Brodsky, L., Du, C. W., Chappell, A., ... \& Ji, W. (2016). A global spectral library to characterize the world's soil. Earth-Science Reviews, 155, 198-230. https://doi.org/10.1016/j. earscirev.2016.01.012

Ruzmi, R., Ahmad-Hamdani, M. S., \& Bakar, B. B. (2017). Prevalence of herbicide-resistant weed species in Malaysian rice fields: A review. Weed Biology and Management, 17(1), 3-16. https://doi.org/10.1111/ wbm. 12112

$\mathrm{Su}$, W. H. (2020). Advanced machine learning in point spectroscopy, RGB-and hyperspectral-imaging for automatic discriminations of crops and weeds: A review. Smart Cities, 3(3), 767-792. https://doi. org/10.3390/smartcities3030039

Sudianto, E., Neik, T. X., Tam, S. M., Chuah, T. S., Idris, A. A., Olsen, K. M., \& Song, B. K. (2016). Morphology of Malaysian weedy rice (Oryza sativa): Diversity, origin and implications for weed management. Weed Science, 64(3), 501-512. https://doi.org/10.1614/WS-D-15-00168.1

Tang, J. L., Chen, X. Q., Miao, R. H., \& Wang, D. (2016). Weed detection using image processing under different illumination for site-specific areas spraying. Computers and Electronics in Agriculture, 122, 103-111. https://doi.org/10.1016/j.compag.2015.12.016

Vaghefi, N., Shamsudin, M. N., Radam, A., \& Rahim, K. A. (2016). Impact of climate change on food security in Malaysia: economic and policy adjustments for rice industry. Journal of Integrative Environmental Sciences, 13(1), 19-35. https://doi.org/10.1080/1943815X.2015.1112292

Vigueira, C. C., Qi, X., Song, B. K., Li, L. F., Caicedo, A. L., Jia, Y., \& Olsen, K. M. (2019). Call of the wild rice: Oryza rufipogon shapes weedy rice evolution in Southeast Asia. Evolutionary applications, 12(1), 93-104. https://doi.org/10.1111/eva.12581 
Wendel, A., \& Underwood, J. (2016). Self-supervised weed detection in vegetable crops using ground based hyperspectral imaging. In 2016 IEEE international conference on robotics and automation (ICRA) (pp. 5128-5135). IEEE Publishing. https://doi.org/10.1109/ICRA.2016.7487717

Yang, X. F., \& Kong, C. H. (2017). Interference of allelopathic rice with paddy weeds at the root level. Plant Biology, 19(4), 584-591. https://doi.org/10.1111/plb.12557

Yuhao, A., Che'Ya, N. N., Roslin, N. A., \& Ismail, M. R. (2020). Rice chlorophyll content monitoring using vegetation indices from multispectral aerial imagery. Pertanika Journal of Science \& Technology, 28(3), 779-795.

Zhang, D., Wang, D., Du, Z., Huang, L., Zhao, H., Liang, D., Gu, C., \& Yang, X. (2019). A rapidly diagnosis and application system of fusarium head blight based on smartphone. In 2019 8th International Conference on Agro-Geoinformatics (Agro- Geoinformatics) (pp. 1-5). IEEE Publishing. https://doi.org/10.1109/ Agro-Geoinformatics.2019.8820529 
